\title{
Triacylglycerols profile as a chemical tool to identify mushrooms submitted to gamma or electron beam irradiation
}

\author{
Ângela Fernandes ${ }^{\mathrm{a}, \mathrm{b}}$, João C.M. Barreira, ${ }^{\mathrm{a}, \mathrm{b}}$, Amilcar L. Antonio, ${ }^{\mathrm{a}, \mathrm{c}, \mathrm{d}}$, Anabela Martins ${ }^{\mathrm{a}}$, \\ Isabel C.F.R. Ferreira, ${ }^{\mathrm{a},}$, M. Beatriz P.P. Oliveira ${ }^{\mathrm{b}}$
}

${ }^{a}$ Centro de Investigação de Montanha, ESA, Instituto Politécnico de Bragança, Campus de Santa Apolónia, Apartado 1172, 5301-855 Bragança, Portugal.

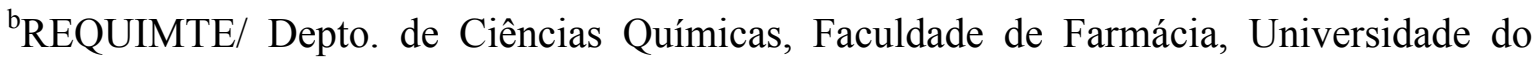
Porto, Rua Jorge Viterbo Ferreira n. ${ }^{\circ} 228,4050-313$ Porto, Portugal.

'IST/ITN, Instituto Tecnológico e Nuclear, Estrada Nacional 10, 2686-953 Sacavém, Portugal.

${ }^{\mathrm{d} D e p a r t a m e n t o ~ d e ~ F i ́ s i c a ~ F u n d a m e n t a l, ~ U n i v e r s i d a d e ~ d e ~ S a l a m a n c a, ~ P l a z a ~ d e ~ l a ~ M e r c e d, ~}$ 37008 Salamanca, Spain.

\footnotetext{
*Author to whom correspondence should be addressed (I.C.F.R. Ferreira: iferreira@ipb.pt, tel. +351-273303219, fax +351-273325405).
} 


\begin{abstract}
In order to define irradiation treatment as a routine conservation methodology, it is imperative to develop chemometric indicators with the ability to distinguish irradiated from unirradiated foodstuffs. Electron spin resonance, photostimulated luminescence and thermoluminescence methods were employed to monitor radiation-induced markers, as well as different chemical compounds produced from the lipidic fraction of different foodstuffs. Otherwise, the specificity of triacylglycerol profiles was previously detected in mushroom species, as also the effect of irradiation treatment in the triacylglycerol profiles of chestnut. Accordingly, its feasibility as chemometric indicator of irradiated mushrooms was evaluated. In line with the obtained results, the effects of each type of irradiation were significantly different, as it can be concluded from the correlations among discriminant functions and variables within each statistical test. Triacylglycerol profile proved to be a useful tool to detect irradiated mushrooms, independently of the species or irradiation source, especially for doses above $1 \mathrm{kGy}$.
\end{abstract}

Keywords: Triacylglycerols; wild mushrooms; gamma irradiation; electron beam; chemometrics. 


\section{Introduction}

Mushrooms are widely appreciated foods due to their nutritional, organoleptic (Kalač, 2009) and pharmacological properties (Lindequist, Niedermeyer \& Jülich, 2005). Nevertheless, mushrooms shelf life is very short due to several postharvest changes related to the high respiration rate and lack of physical protection to avoid water loss or bacteria and moulds attack, which results in weight loss and browning (Fernandes, Antonio, Oliveira, Martins, \& Ferreira, 2012). Irradiation is a conservation/preservation technique that can minimize the mentioned losses, contributing to extend foods shelf life and reducing health hazards (Soika \& Delincée, 2000).

The specific effects of radiation on mushrooms chemical composition and antioxidant activity have been progressively studied by our research group, either using gamma irradiation (Fernandes et al., 2013a) or electron beam treatment (Fernandes et al., 2013b).

The existence of tests capable of distinguishing irradiated from unirradiated foodstuffs is imperative, in order to regulate international trade and guarantee freedom of choice to the consumer (Ndiaye, Jamet, Miesch, Hasselmann, \& Marchioni, 1999). The European Committee for Standardization validated methods to identify irradiated foods; these methods are based on the study of primary radiolytic products by Electron Paramagnetic Resonance (EPR) and thermoluminescence, or on the analysis of certain chemical compounds (e.g., volatile hydrocarbons and 2-alkylcyclobutanones) formed by the radiolysis of triglycerides (Ndiaye et al., 1999). The European Union (EU) adopted Directives 1999/2/EC and 1999/3/EC to standardize the rules of processing and marketing of irradiated foods in countries of EU for consumer protection and information (Alberti et al., 2011). At the European level, there are official protocols for the electron spin resonance (ESR) detection of irradiated foodstuffs containing bone structures (EN 1786, 1996; Alberti et al., 2011), cellulose (EN 1787, 2000; Alberti et al., 2011) or crystalline 
sugar (EN 13708, 2001; Alberti et al., 2011). Several ESR studies were made for the identification of irradiated seafood: fishes, crustacean, shrimps and mollusks (Alberti et al., 2011). Regarding fatty foods, the main methods are based on the chemical determination of compounds formed from the irradiation of lipid components; 2-alkylcyclobutanones (2ACBs) are produced by the irradiation of fatty acids and glycerides (Crews, Driffield, \& Thomas, 2012). 2-Dodecylcyclobutanone (2-DCB) (Blanch, Caja, Flores, \& Castillo, 2009), produced from palmitic acid specifically by radiolysis (Ndiaye et al., 1999) and the alkane hydrocarbons were used as irradiation markers in sliced dry-cured ham. These two compounds were evaluated by solid phase microextraction (SPME)-gas chromatographymass spectrometry (GC-MS) (Blanch et al., 2009). Otherwise, gamma irradiation of papaya resulted in the appearance of a new peak in the GC-MS, which was identified as phenol, functioning as a marker of this irradiated food (Chatterjee, Variyar, \& Sharma, 2012). Photostimulated luminescence (PSL) and thermoluminescence (TL) methods were also employed to monitor radiation-induced markers in gamma ray and electron beam irradiated wheat after different processing treatments (Kim, Akram, Ahn, \& Kwon, 2012). Triacylglycerols (TAG) profile is specific of each natural matrix and it has been used for detecting adulteration of fats and oils, crystallization and recognition of oil origins, being one of the prime determinants in the study of oil oxidation (Zeb, 2012; Barreira et al. 2013). It can also act as a quality marker in roasted coffee (Toci, Neto, Torres, \& Farah, 2013) and was also pointed out as a chemical taxonomical marker for mushrooms (Barreira, Ferreira, Oliveira, \& 2012).

Therefore, the potential of using TAG profile as a marker for detecting irradiated foods and, in particular, mushrooms, was evaluated. In order to achieve a high broad irradiation marker, samples from mushrooms submitted to different industrial processing, irradiation type and dose were used. 


\section{Materials and methods}

\subsection{Standards and reagents}

Triacylglycerols 1,2,3-tripalmitoylglycerol (PPP), 1,2,3-tristearoylglycerol (SSS), 1,2,3trilinolenoylglycerol ( $\operatorname{LnLnLn})$, and 1,2,3-tripalmitoleoylglycerol (PoPoPo), of purity > 98\%, and 1,2,3- trioleoylglycerol (OOO), 1,2,3-trilinoleoylglycerol (LLL), 1,2-dilinoleoyl3-palmitoyl-rac-glycerol (PLL), 1,2-dilinoleoyl-3-oleoylrac- glycerol (OLL), 1,2dipalmitoyl-3-oleoyl-rac-glycerol (PPO), 1,2-dioleoyl-3-stearoyl-rac-glycerol (SOO), 1palmitoyl-2-oleoyl-3-linoleoylglycerol (POL), and 1,2-dioleoyl-3-palmitoyl-racglycerol (POO), of $\approx 99 \%$ purity, were purchased from Sigma (St. Louis, MO, USA). Petroleum ether was analytical grade and obtained from Fisher Scientific (Leicestershire, UK). Acetonitrile and acetone were HPLC grade and obtained from Merck (Darmstadt, Germany). The code letters used for the fatty acids are: L, linoleic; Ln, linolenic; O, oleic; P, palmitic; Po, palmitoleic; S, stearic.

\subsection{Samples}

Macrolepiota procera, Boletus edulis, Russula delica and Boletus pinophilus were collected in Trás-os-Montes, in the Northeast of Portugal; the first two mushroom species were collected in November 2011 and the other species were collected in November 2012. B. edulis fruiting bodies were divided in two groups with twelve mushrooms per group, and further submitted to drying (at $30^{\circ} \mathrm{C}$ in an oven) or kept fresh (stored at $4{ }^{\circ} \mathrm{C}$ in a refrigerator). Drying samples group was then subdivided in three subgroups submitted to gamma irradiation: control (non-irradiated, $0 \mathrm{kGy}$ ), sample 1 (irradiated with $1 \mathrm{kGy}$ ) and sample 2 (irradiated with $2 \mathrm{kGy}$ ), with 4 mushrooms per subgroup; fresh samples group 
was subdivided in four subgroups treated with electron-beam irradiation: control (nonirradiated, $0 \mathrm{kGy}$ ), sample 1 (irradiated with $2 \mathrm{kGy}$ ), sample 2 (irradiated with $6 \mathrm{kGy}$ ) and sample 3 (irradiated with $10 \mathrm{kGy}$ ) with 3 mushrooms per subgroup.

M. procera fruiting bodies were divided in three groups with nine mushrooms per group, and further submitted to different processing technologies: freezing (at $-20^{\circ} \mathrm{C}$ in a freezer), drying (at $30{ }^{\circ} \mathrm{C}$ in an oven) and the third group was kept fresh (stored at $4{ }^{\circ} \mathrm{C}$ in a refrigerator). Each group was further subdivided in three subgroups: control (nonirradiated, $0 \mathrm{kGy}$ ); sample 1 (irradiated with $0.5 \mathrm{kGy}$ ) and sample 2 (irradiated with 1 kGy).

Besides the former mushrooms, which stand among the species producing in highest quantity, two additional species were studied. A second Boletus species (B. pinophilus) was studied following the same sampling used for B. edulis fresh samples, except the intermediate dose, which was not tested.

A brittlegill mushroom ( $R$. delica) was also studied as an example of a less appreciated, despite edible, species. The same sampling as that used for B. edulis dried samples was followed, except for the higher number (6) of samples per group.

All the samples were lyophilized (FreeZone 4.5 model 7750031, Labconco, Kansas, USA), reduced to a fine dried powder (20 mesh) and mixed to obtain homogenized samples for subsequent analysis.

\subsection{Samples irradiation}

\subsubsection{Gamma irradiation}

The irradiation of the samples was performed in a Co-60 experimental chamber with four sources, total activity $198 \mathrm{TBq}(5.33 \mathrm{kCi})$, in November 2012 (Precisa 22, Graviner Manufacturing Company Ltd, U.K.). After irradiation geometry dose rate estimation, using 
the Fricke dosimeter and the procedure described in the standards (ASTM, 1992), all groups were placed in Poly(methyl methacrylate) (PMMA) box, or acrylic glass, and irradiated at ambient atmosphere and temperature $\left(15^{\circ} \mathrm{C}\right)$. To monitor the process during the irradiation, 4 routine dosimeters were used for each group for the higher dose (Amber Perspex dosimeters, batch V, from Harwell company, U.K.). The samples were rotated upside down $\left(180^{\circ}\right)$ at half of the time, to increase the dose uniformity. The Amber Perspex dosimeters were read in a UV-VIS Spectrophotometer (Shimadzu mini UV 1240 spectrophotometer) at $603 \mathrm{~nm}$, two readings for each, to estimate the dose according to a previous calibration curve.

The estimated doses after irradiation for $M$. procera were $0.6 \pm 0.1 \mathrm{kGy}$ and $1.1 \pm 0.1 \mathrm{kGy}$ for samples 1 and 2, respectively, at a dose rate of $2.3 \mathrm{kGy} \mathrm{h}^{-1}$. The estimated doses and dose rates were: $1.14 \pm 0.23 \mathrm{kGy}, 1.71 \mathrm{kGy} \mathrm{h}^{-1}$ and $1.99 \pm 0.32 \mathrm{kGy}, 1.49 \mathrm{kGy} \mathrm{h}^{-1}$ for $B$. edulis sample 1 and 2 respectively; for $B$. pinophilus, the estimated doses and dose rates were: $2.09 \pm 0.16 \mathrm{kGy}$ and $1.57 \mathrm{kGy} \mathrm{h}^{-1}$.

\subsubsection{Electron beam irradiation}

For B. edulis and R. delica the irradiation was performed at the INCT - Institute of Nuclear Chemistry and Technology, in Warsaw, Poland. To estimate the dose during the irradiation process three types of dosimeters were used a standard dosimeter, graphite calorimeter, and two routine dosimeters, Gammachrome YR and Amber Perspex, from Harwell Company (UK). The irradiation took place in an e-beam irradiator of $10 \mathrm{MeV}$ of energy with pulse duration of $5.5 \mu \mathrm{s}$, a pulse frequency of $440 \mathrm{~Hz}$, and an average beam current of $1.1 \mathrm{~mA}$; the scan width was $68 \mathrm{~cm}$, the conveyer speed was settled to the range $20-100 \mathrm{~cm} / \mathrm{min}$ and the scan frequency was $5 \mathrm{~Hz}$. The estimated absorbed doses were 2.5, 6.2 and 10.9 kGy, with an uncertainty of 20\%. To read Amber and Gammachrome YR dosimeters, 
spectrophotometric methods were used at $603 \mathrm{~nm}$ and at $530 \mathrm{~nm}$, respectively, to estimate the dose from the value of absorbance according to a previous calibration curve. For the Graphite calorimeter dosimeter the electrical resistance was read and converted in dose according to a previous calibration curve (Carocho et al., 2012).

\subsection{Triacylglycerols analysis}

Each sample $(\sim 3 \mathrm{~g})$ was then submitted to an extraction with petroleum ether $\left(40-60{ }^{\circ} \mathrm{C}\right)$ performed in Soxhlet apparatus for $1.5 \mathrm{~h}$. The chromatographic analyses were carried out according to the procedure previously described (Barreira, Casal, Ferreira, Oliveira, \& Pereira, 2009), with a Jasco (Tokyo, Japan) HPLC system, equipped with a PU-1580 quaternary pump and a Jasco AS-950 automatic sampler with a $10 \mu \mathrm{L}$ loop. Detection was performed with an evaporative light-scattering detector (ELSD) (model 75-Sedere, Alfortville, France). The chromatographic separation of the compounds was achieved with a Kromasil $100 \mathrm{C}_{18}(5 \mu \mathrm{m} ; 250 \mathrm{~mm} \times 4.6 \mathrm{~mm})$ column (Teknokroma, Barcelona, Spain) operating at room temperature $\left(\approx 20^{\circ} \mathrm{C}\right)$. The mobile phase was a mixture of acetone and acetonitrile (70:30), in an isocratic mode, at an elution rate of $1 \mathrm{~mL} / \mathrm{min}$. Detection was performed with an evaporative light-scattering detector (ELSD) (model 75-Sedere, Alfortville, France) with the following settings: evaporator temperature $40{ }^{\circ} \mathrm{C}$, air pressure 3.5 bar and photomultiplier sensitivity 6 . Taking into account the selectivities ( $R$, relative retention times to LLL), peaks were identified according to the logarithms of $\mathrm{R}$ in relation to homogeneous TAG standards. Quantification of the peaks was made by internal normalization of chromatographic peak area, and the results were expressed in relative percentage, assuming that the detector response was the same for all the compounds within each analysis. Data were analyzed using the Borwin-PDA Controller Software (JMBS, France). 


\subsection{Statistical analysis}

For each combination of processing technology, irradiation type and dose, three samples were analysed, with all the assays being also carried out in triplicate. Data were expressed as mean \pm standard deviation. All statistical tests were performed at a $5 \%$ significance level using SPSS software, version 18.0.

\subsubsection{Analysis of variance}

The fulfilment of the one-way ANOVA requirements, specifically the normal distribution of the residuals and the homogeneity of variance, was tested by means of the Shapiro Wilk's and the Levene's tests, respectively. All dependent variables were compared using Tukey's honestly significant difference (HSD) or Tamhane's T2 multiple comparison tests, when homoscedasticity was verified or not, respectively. Results obtained for B. pinophilus were classified using a simple $t$-test for equality of means (after checking the equality of variances through a Levene's test), since there were fewer than three groups.

\subsubsection{Stepwise Linear Discriminant Analysis (LDA)}

LDA was used to check for significant differences in TAG profiles in result of being submitted to different processing technologies, irradiation types and doses. A stepwise technique, using the Wilks' $\lambda$ method with the usual probabilities of $F$ (3.84 to enter and 2.71 to remove), was applied to select variables. This procedure follows a combination of forward selection and backward elimination steps; i.e., before a new variable is selected to be included, it is verified whether all previously selected variables remain significant (Cunha \& Oliveira, 2006; Hill \& Lewicki, 2006). The combination of varieties is defined in a way that the first function furnishes the most general discrimination between groups, 
the second provides the second most, and so on (López, García, \& Garrido, 2008). To verify which canonical discriminant functions were significant, the Wilks' $\lambda$ test was applied. To keep a more realistic data modulation, a leave-one-out cross-validation procedure was carried out to assess the model performance. Moreover, the sensibility and specificity of the discriminant model were computed from the number of individuals correctly predicted as belonging to an assigned group (Benitez, Nogales, Campos, \& Ruano, 2006). Sensibility was calculated by dividing the number of samples of a specific group correctly classified by the total number of samples belonging to that specific group. Specificity was calculated by dividing the number of samples of a specific group classified as belonging to that group by the total number of samples of any group classified as belonging to that specific group.

\section{Results and discussion}

In a previous work conducted to evaluate the usefulness of mushrooms' triacylglycerol (TAG) profile as a chemical fingerprint for different taxonomic ranks, the highest intrinsic differences were found among mushroom species, indicating a high degree of specificity, possibly derived from the genetic control of the stereospecific distribution of fatty acids on the glycerol molecule (Barreira, Ferreira, \& Oliveira, 2012). In addition, the effects of gamma and electron-beam irradiation on TAG profiles were also reported as being significant, especially with the highest doses ( 1 and $3 \mathrm{kGy}$ in both cases), in a study performed on chestnut samples.

Accordingly, TAG profiles in mushrooms submitted to different irradiation types and doses were characterized. Four mushroom species were selected, using samples processed according to the most common industrial availability (fresh, dried and frozen) for wild edible mushrooms. 
Table 1 shows the mean values obtained for TAG profiles of each mushroom species, according to the processing type and irradiation treatment. The values are presented in relative percentage due to limitations in the availability of high-purity standards. Nevertheless, the peak areas might be readily converted into relative TAG concentration, assuming linearity and uniformity of the detector signal, regardless of the TAG molecule and absolute concentration (Rombaut, De Clercq, Foubert, \& Dewettinck, 2009). The usual chromatographic elution order is ttt, stt, mtt, stt, ddt, mdt, sdt, ddd, mmt, smt, mdd, sst, sdd, $\mathrm{mmd}, \mathrm{smd}, \mathrm{mmm}, \mathrm{ssd}, \mathrm{smm}, \mathrm{ssm}$ and sss $(\mathrm{s}=$ saturated, $\mathrm{m}=$ monoenoic, $\mathrm{d}=$ dienoic and $\mathrm{t}=$ trienoic acids (Fuchs et al., 2011). TAGs quantified in Table $\mathbf{1}$ followed the expected order: LLnLn (dtt), LLL (ddd), OLL (mdd), PLL (sdd), OOL (mmd), POL (smd), OOO (mmm), POO (smm), PPO (ssm), SPO (ssm) and SPP (sss), except for SOO (smm). In this first set of data, mean values were calculated for each irradiation dose, irradiation source and processing type. As a preliminary overview, it is possible to conclude that the effect of electron-beam irradiation is more pronounced than that obtained for gamma irradiation (except for dried M. procera samples), as it can be observed by the $p$-values for 1-way ANOVA test. However, this result might be explained by the higher doses used in electron-beam irradiation, instead of the irradiation source. Following the same reasoning, changes in dried samples were more evident than those verified in fresh or frozen samples. Regarding some particular changes, the Levene test showed that the assumption of equality among variances could be made in most cases, allowing applying Tukey test as a multiple comparison test. In the remaining cases samples were classified by means of the Tamhanes' T2 test.

Fresh B. edulis samples submitted to gamma irradiation presented higher percentages of OLL and POL and less OOL, OOO and PPO, especially for $1 \mathrm{kGy}$ dose. The effects of electron-beam in dried samples of the same mushroom were particularly observable for 6 
and $10 \mathrm{kGy}$ doses, which produced similar changes: higher percentages in LLL and OLL and lower percentages in OOL, OOO and PPO.

Results obtained for B. pinophilus were classified using a simple $t$-test for equality of means (after checking the equality of variances through a Levene's test), since less than three groups were available. OLL, OOL and POO showed to be significantly higher in irradiated samples, while OOO, PPO, SOO and SPO presented higher values in unirradiated samples.

Concerning $M$. procera, the effects of gamma irradiation were more marked in dried samples, since the mean value of at least one dose differs from the others for all TAG. Among fresh samples, irradiation tended to increase LLL, POL, POO and PPO percentages; the same effect was observable for LLL, OOO, POO and PPO in dried samples and OLL and POL in frozen samples. On the other hand, fresh unirradiated samples presented higher contents in OLL, PLL, dried unirradiated samples in OOL and POL, and unirradiated frozen samples in OOO, POO and PPO.

In line with the observed for $B$. edulis, the effects of electron-beam irradiation were significant for most TAG molecules quantified in $R$. delica samples: LLL, POO and SPO had maximum percentages in samples irradiated with a $10 \mathrm{kGy}$ dose, while OLL and POL were highest in unirradiated samples, which simultaneously presented the least values in OOO, SOO and SPO.

The significant differences found among the mean values for each TAG were a good preliminary indicator of TAG profiles' ability to act as an irradiation treatment indicator. This assumption was checked by applying different linear discriminant analyses (LDA), chosen as a supervised classification technique. Primarily, it was intended to verify if the significant differences among irradiated and unirradiated samples could be enough to recommend TAG analysis as a reliable indicator of irradiation treatment independently of 
general state of mushrooms (fresh, dried or frozen), irradiation type (gamma or electronbeam) and irradiation doses $(0,0.5,1.0,2.0,6.0$ or 10.0 , depending on each case).

Since the driving force was finding differences among irradiated and unirradiated samples in a general way, and the assayed mushrooms presented qualitative and quantitative differences in their TAG profiles, the set of data was normalized to overcome unrealistic results derived from biased results such as differences in TAG profiles of each control. The applied normalization consisted of calculating relative differences among each quantified value (irradiated samples) and its respective control (unirradiated samples). Hence, LDA was applied to the relative differences found for all measurements and not to the absolute values presented in Table 1.

The significant independent variables (TAG) were selected using the stepwise procedure of the LDA, according to the Wilks' ë test. Only variables with a statistically significant classification performance $(p<0.05)$ were kept in the analysis.

In the first approach, all doses (for both irradiation types) were used as grouping variables. In this case, 5 significant functions were defined, from which the first three were plotted (Figure 1). The three plotted functions integrated $95.1 \%$ of the observed variance (first, $68.1 \%$; second, $16.5 \%$; third, $10.5 \%$ ). As can be observed, the naturally occurring groups (each assayed dose) were not individually clustered. Nevertheless, the classification performance was satisfactory, resulting in $69 \%$ of correctly classified samples (sensitivity) within the leave-one-out cross-validation procedure (Table 2). All unirradiated samples were correctly classified and none of samples irradiated with 6 or $10 \mathrm{kGy}$ resulted in a false negative (unirradiated). Hence, the obtained model seems to be effective to detect irradiation treatment above $2 \mathrm{kGy}$, independently of irradiation source. The satisfactory performance of the proposed classification procedure is also confirmed by the overall specificity (72\%) achieved for the cross-validation procedure. The analysis kept SPO, 
LLL, PLL, SPP, OOL and SOO in the final discriminant model, being verified that OOL and SPO were the variables with highest correlation with function 1, SPO and SPP with function 2 and PLL and LLL with function 3.

In order to abolish the effect of irradiation type, two additional LDA were applied fixing the results obtained for gamma and electron-beam irradiation treatment. In the first case, the discriminant model was defined with 3 significant functions (Figure 2a), which included $100.0 \%$ of the observed variance (function $1: 92.7 \%$, function $2: 5.0 \%$, function 3: $2.3 \%)$. The model showed a better classification performance (sensitivity $=77 \%)$. In fact, as can be observed from Table 2, all unirradiated samples were correctly classified and none of samples irradiated with $2 \mathrm{kGy}$ resulted in a false negative (unirradiated). Hence, the obtained model seems to be effective to detect gamma irradiation treatment above $1 \mathrm{kGy}$. The satisfactory performance of the proposed classification procedure is also confirmed by the overall specificity $(80 \%)$ achieved for the cross-validation procedure. SPP, POL (more correlated with the first function), LLL, PPO (more correlated with the second function), LLnLn, OOL and POO (more correlated with the third function) were the variables kept in the final discriminant model.

Regarding e-beam irradiation, the discriminant model selected also 3 significant functions (Figure 2b), which included $100.0 \%$ of the observed variance (function 1: $76.2 \%$, function 2: $16.2 \%$, function 3: $7.6 \%$ ). The model showed a similar classification performance $($ sensitivity $=78 \%)$. Once again, the unirradiated samples were correctly classified in all cases; furthermore, none of samples irradiated with 6 or $10 \mathrm{kGy}$ resulted in a false negative, allowing considering the feasibility of the model to detect electron-beam irradiation treatment above $2 \mathrm{kGy}$. The performance of the proposed classification procedure is also confirmed by the overall specificity (78\%) achieved for the crossvalidation procedure. SPO, LLL (more correlated with the first function), OOO, SOO and 
PPO (more correlated with the second function), were the variables kept in the final discriminant model.

Overall, TAG profile might be a practical tool to detect irradiated mushrooms, independently of mushroom species or irradiation source. The effects of each type of irradiation were significantly different, as it can be concluded from the correlations among discriminant functions and variables within each statistical test. The suggested chemometric parameter was more reliable for the higher assayed doses, indicating that the lowest doses had only a slight effect on TAG profiles. Other mushrooms species might be scrutinized in order to increase the broadness of application of this particular chemometric indicator.

\section{Acknowledgements}

Authors are grateful to the Foundation for Science and Technology (FCT, Portugal) for financial support to research centres CIMO (PEst-OE/AGR/UI0690/2011) and REQUIMTE (PEst-C/EQB/LA0006/2011). Â. Fernandes, J.C.M. Barreira and A.L. Antonio thank FCT, POPH-QREN and FSE for their grants (SFRH/BD/76019/2011, SFRH/BPD/72802/2010 and SFRH/PROTEC/67398/2010, respectively). The authors also thank Prof. A. Chmielewski and Dr. A. Rafalski, from Institute of Nuclear Chemistry and Technology, Warsaw, Poland, for electron beam irradiations.

\section{References}

Alberti, A., Chiaravalle, E., Fuochi, P., Macciantelli, D., Mangiacotti, M., Marchesani, G., \& Plescia, E. (2011). Irradiated bivalve mollusks: Use of EPR spectroscopy for identification and dosimetry. Radiation Physics and Chemistry, 80, 1363-1370. 
ASTM, American Society for Testing and Materials. (1992). Practice for Using the Fricke Reference Standard Dosimetry System, ASTM E1026. Annual Book of ASTM Standards, 12.02, Philadelphia, PA.

Barreira, J.C.M., Casal, S., Ferreira, I.C.F.R., Oliveira, M.B.P.P., \& Pereira, J.A. (2009). Nutritional, fatty acid and triacylglycerol profiles of Castanea sativa Mill. cultivars: a compositional and chemometric approach. Journal of Agricultural and Food Chemistry, 57, 2836-2842.

Barreira, J.C.M, Ferreira, I.C.F.R., \& Oliveira, M.B.P.P. (2012). Triacylglycerol profile as a chemical fingerprint of mushroom species: evaluation by principal component and linear discriminant analyses. Journal of Agricultural and Food Chemistry, 60, 10592-10599.

Barreira, J.C.M., Carocho, M., Ferreira, I.C.F.R., Antonio, A.L., Kaluska, I., Botelho, M. L., Bento, A., \& Oliveira, M.B.P.P. (2013). Effects of gamma and electron beam irradiations on the triacylglycerol profile of fresh and stored Castanea sativa Miller samples. Postharvest Biology and Technology, 81, 1-6.

Benitez, E., Nogales, R., Campos, M., \& Ruano, F. (2006). Biochemical variability of olive-orchard soils under different management systems. Applied Soil Ecology, 32, $221-231$

Blanch, G.P., Caja, M.M., Flores, G., \& Castillo, M.L.R. (2009). Identification of 2dodecylcyclobutanone and linear-alkanes as irradiation markers in sliced dry-cured ham. Food Chemistry, 113, 616-620.

Carocho, M., Barreira, J.C.M., Antonio, A.L., Bento, A., Kaluska, I., \& Ferreira, I.C.F.R. (2012). Effects of Electron Beam Radiation on Nutritional parameters of Portuguese Chestnuts (Castanea sativa Mill). Journal of Agricultural and Food Chemistry, 60, 7754-7760. 
Chatterjee, S., Variyar, P.S., \& Sharma, A. (2012). Post-irradiation identification of papaya (Carica papaya L.) fruit. Radiation Physics and Chemistry, 81, 352-353.

Crews, C., Driffield, M., \& Thomas, C. (2012). Analysis of 2-alkylcyclobutanones for detection of food irradiation: Current status, needs and prospects. Journal of Food Composition and Analysis, 26, 1-11.

Cunha, S.C., \& Oliveira, M.B.P.P. (2006). Discrimination of vegetable oils by triacylglycerols evaluation of profile using HPLC/ELSD. Food Chemistry, 95, 518524.

EN 1786. (1996). Foodstuffs: detection of irradiated food containing bone - method by ESR spectroscopy. European Committee of Standardization (CEN), Brussels.

EN 1787. (2000). Foodstuffs: detection of irradiated food containing cellulose by ESR spectroscopy. European Committee of Standardization (CEN), Brussels.

EN 13708 (2001). Foodstuffs: detection of irradiated food containing crystalline sugar by ESR spectroscopy. European Committee of Standardization (CEN), Brussels.

Fernandes, Â., Antonio, A.L., Oliveira, M.P.P., Martins, A., \& Ferreira, I.C.F.R. (2012). Effect of gamma and electron beam irradiation on the physico-chemical and nutritional properties of mushrooms: A review. Food Chemistry, 135, 641-650.

Fernandes, Â., Antonio, A.L., Barreira, J.C.M., Botelho, L., Oliveira, M.B.P.P., Martins, A., \& Ferreira, I.C.F.R. (2013a). Effects of gamma irradiation on the chemical composition and antioxidant activity of Lactarius deliciosus L. wild edible mushroom. Food and Bioprocess Technology, 6, 2895-2903.

Fernandes, Â., Barreira, J.C.M., Antonio, A.L., Oliveira, M.B.P.P., Martins, A., \& Ferreira, I.C.F.R. (2013b). Combined effects of electron-beam irradiation and storage time on the chemical and antioxidant parameters of wild Macrolepiota procera dried samples. Food Bioprocess Technology. DOI 10.1007/s11947-013-1179-4. 
Fuchs, B., Rosmarie, Suss R., Teuber, K., Eibisch, M., \& Schiller, J. (2011). Lipid analysis by thin-layer chromatography- A review of the current state. Journal of Chromatography A, 1218, 2754-2774.

Hill, T., \& Lewicki, P. (2006). Statistics: Methods and Applications. A Comprehensive Reference for Science, Industry, and Data Mining; StatSoft: Tulsa, OK, USA.

Kalač, P. (2009). Chemical composition and nutritional value of European species of wild growing mushrooms: A review. Food Chemistry, 113, 9-16.

Kim, G.-R., Akram, K., Ahn, J.-J., \& Kwon, J.-H. (2012). Identification of gamma ray and electron-beam irradiated wheat after different processing treatments. Journal of Cereal Science, 56, 347-351.

Lindequist, U., Niedermeyer, T.H.J., \& Jülich, W.-D. (2005). The Pharmacological Potential of Mushrooms - review. eCAM, 3, 285-299.

López, A., García, P., \& Garrido, A. (2008). Multivariate characterization of table olives according to their mineral nutrient composition. Food Chemistry, 106, 369-378.

Ndiaye, B., Jamet, G., Miesch, M., Hasselmann, C., \& Marchioni, E. (1999). 2Alkylcyclobutanones as markers for irradiated foodstuffs II. The CEN (European Committee for Standardization) method: field of application and limit of utilization. Radiation Physics and Chemistry, 55, 437-445.

Rombaut, R., De Clercq, N., Foubert, I., \& Dewettinck, K. (2009). Triacylglycerol analysis of fats and oils by evaporative light scattering detection. Journal of the American Oil Chemists' Society, 86, 19-25.

Soika, C., \& Delincée, H. (2000). Thermoluminescence analysis for detection of irradiated food - luminescence characteristics of minerals for different types of radiation and radiation doses. Lebensmittel-Wissenschaft \& Technologie, 33, 431-439. 
Toci, A.T., Neto, V.J.M.F., Torres, A.G., \& Farah, A. (2013). Changes in triacylglycerols and free fatty acids composition during storage of roasted coffee. LWT - Food Science and Technology, 50, 581-590.

Zeb, A. (2012). Triacylglycerols composition, oxidation and oxidation compounds in camellia oil using liquid chromatography-mass spectrometry. Chemistry and Physics of Lipids, 165, 608-614. 
Figure 1. Mean scores of different gamma and electron beam irradiation doses (all assembled) projected for the three rotated discriminant functions defined from TAG profiles.

Figure 2. Mean scores of different gamma (a) or electron beam (b) irradiation doses projected for the three rotated discriminant functions defined from TAG profiles. 
Table 1. Triacylglycerol profiles according to processing type, irradiation source and dose. The results are presented as the mean $\pm \mathrm{SD}^{1}$

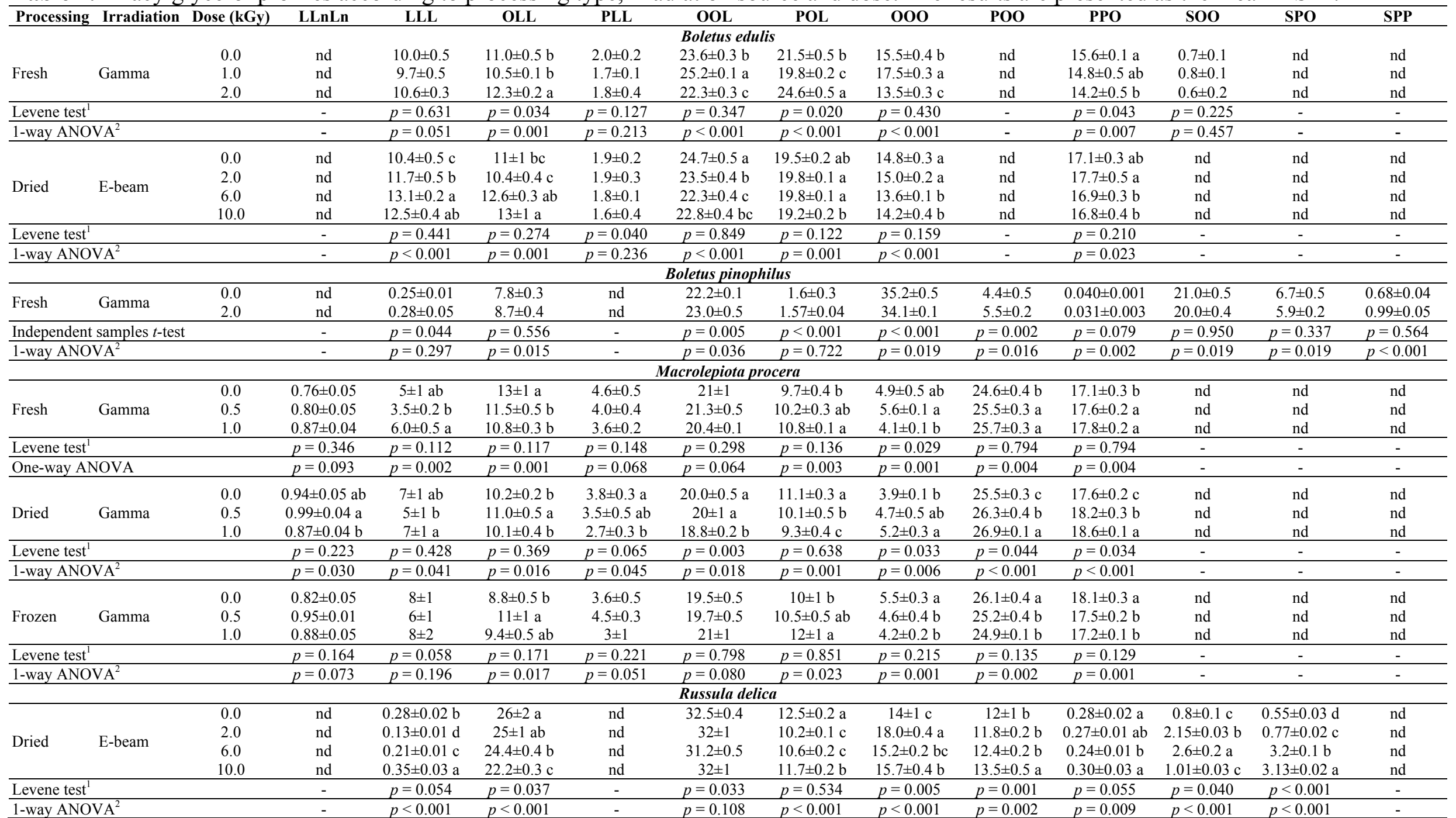

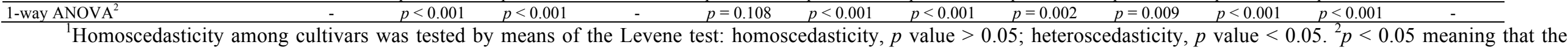
${ }^{1}$ Homoscedasticity among cultivars was tested by means of the Levene test: homoscedasticity, $p$ value $>0.05$; heteroscedasticity, $p$
mean value of the evaluated TAC of at leact nne doce differe from the otherc (in thic race multinle_somnaricon tecte uxere nerformed) 
Table 2. Contingency matrix obtained using LDA based on TAG profiles of species.

\begin{tabular}{|c|c|c|c|c|c|c|c|c|}
\hline \multirow{2}{*}{ Irradiation dose } & \multicolumn{6}{|c|}{ Predicted Group Membership } & \multirow{2}{*}{ Total } & \multirow{2}{*}{ Sensitivit } \\
\hline & $0 \mathrm{kGy}$ & $0.5 \mathrm{kGy}$ & $1 \mathrm{kGy}$ & $2 \mathrm{kGy}$ & $6 \mathrm{kGy}$ & $10 \mathrm{kGy}$ & & \\
\hline \multicolumn{9}{|c|}{ Gamma and electron-beam irradiation } \\
\hline $0 \mathrm{kGy}$ & 28 & 0 & 0 & 0 & 0 & 0 & 28 & 100 \\
\hline $0.5 \mathrm{kGy}$ & 4 & 6 & 2 & 0 & 0 & 0 & 12 & 50 \\
\hline $1 \mathrm{kGy}$ & 2 & 4 & 8 & 2 & 0 & 0 & 16 & 50 \\
\hline $2 \mathrm{kGy}$ & 3 & 1 & 2 & 9 & 1 & 0 & 16 & 56 \\
\hline $6 \mathrm{kGy}$ & 0 & 0 & 0 & 2 & 6 & 0 & 8 & 75 \\
\hline $10 \mathrm{kGy}$ & 0 & 0 & 0 & 3 & 1 & 4 & 8 & 50 \\
\hline total & 37 & 11 & 12 & 16 & 8 & 4 & 88 & 69 \\
\hline Specificity (\%) & 76 & 55 & 67 & 56 & 75 & 100 & 72 & \\
\hline \multicolumn{9}{|c|}{ Gamma irradiation } \\
\hline & $0 \mathrm{kGy}$ & & $.5 \mathrm{kGy}$ & $1 \mathrm{kGy}$ & & $2 \mathrm{kGy}$ & total & Sensitivity \\
\hline $0 \mathrm{kGy}$ & 20 & & 0 & 0 & & 0 & 20 & 100 \\
\hline $0.5 \mathrm{kGy}$ & 5 & & 6 & 1 & & 0 & 12 & 50 \\
\hline $1 \mathrm{kGy}$ & 3 & & 4 & 9 & & 0 & 16 & 56 \\
\hline $2 \mathrm{kGy}$ & 0 & & 0 & 0 & & 8 & 8 & 100 \\
\hline total & 28 & & 10 & 10 & & 8 & 56 & 77 \\
\hline Specificity $(\%)$ & 71 & & 60 & 90 & & 100 & 80 & \\
\hline \multicolumn{9}{|c|}{ Electron-beam irradiation } \\
\hline & $0 \mathrm{kGy}$ & & $2 \mathrm{kGy}$ & $6 \mathrm{kGy}$ & & $10 \mathrm{kGy}$ & total & Sensitivity \\
\hline $0 \mathrm{kGy}$ & 8 & & 0 & 0 & & 0 & 8 & 100 \\
\hline $2 \mathrm{kGy}$ & 1 & & 6 & 0 & & 1 & 8 & 75 \\
\hline $6 \mathrm{kGy}$ & 0 & & 0 & 6 & & 2 & 8 & 75 \\
\hline $10 \mathrm{kGy}$ & 0 & & 1 & 2 & & 5 & 8 & 63 \\
\hline total & 9 & & 7 & 8 & & 8 & 32 & 78 \\
\hline Specificity (\%) & 89 & & 86 & 75 & & 63 & 78 & \\
\hline
\end{tabular}


Figure 1.

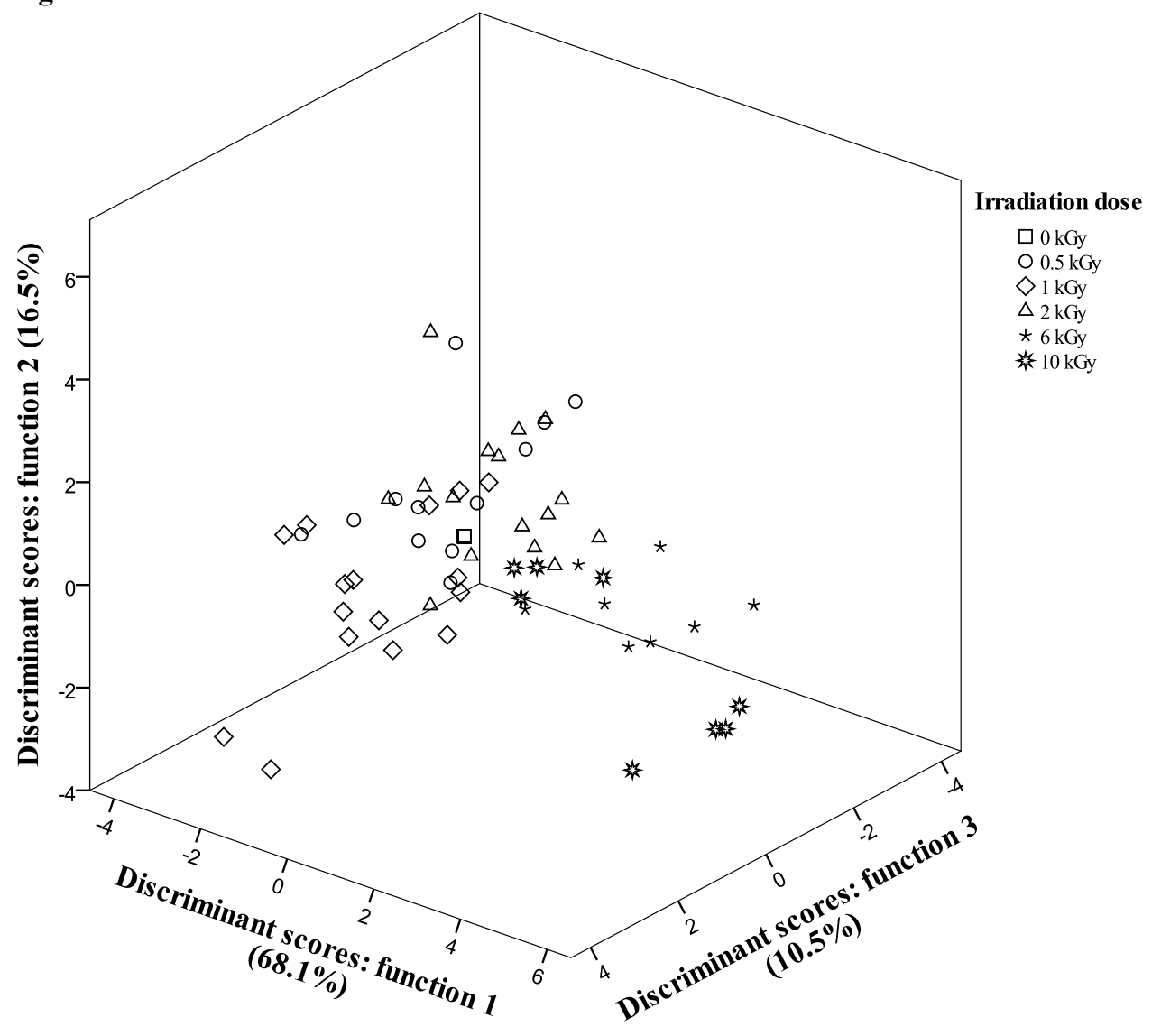


Figure 2.

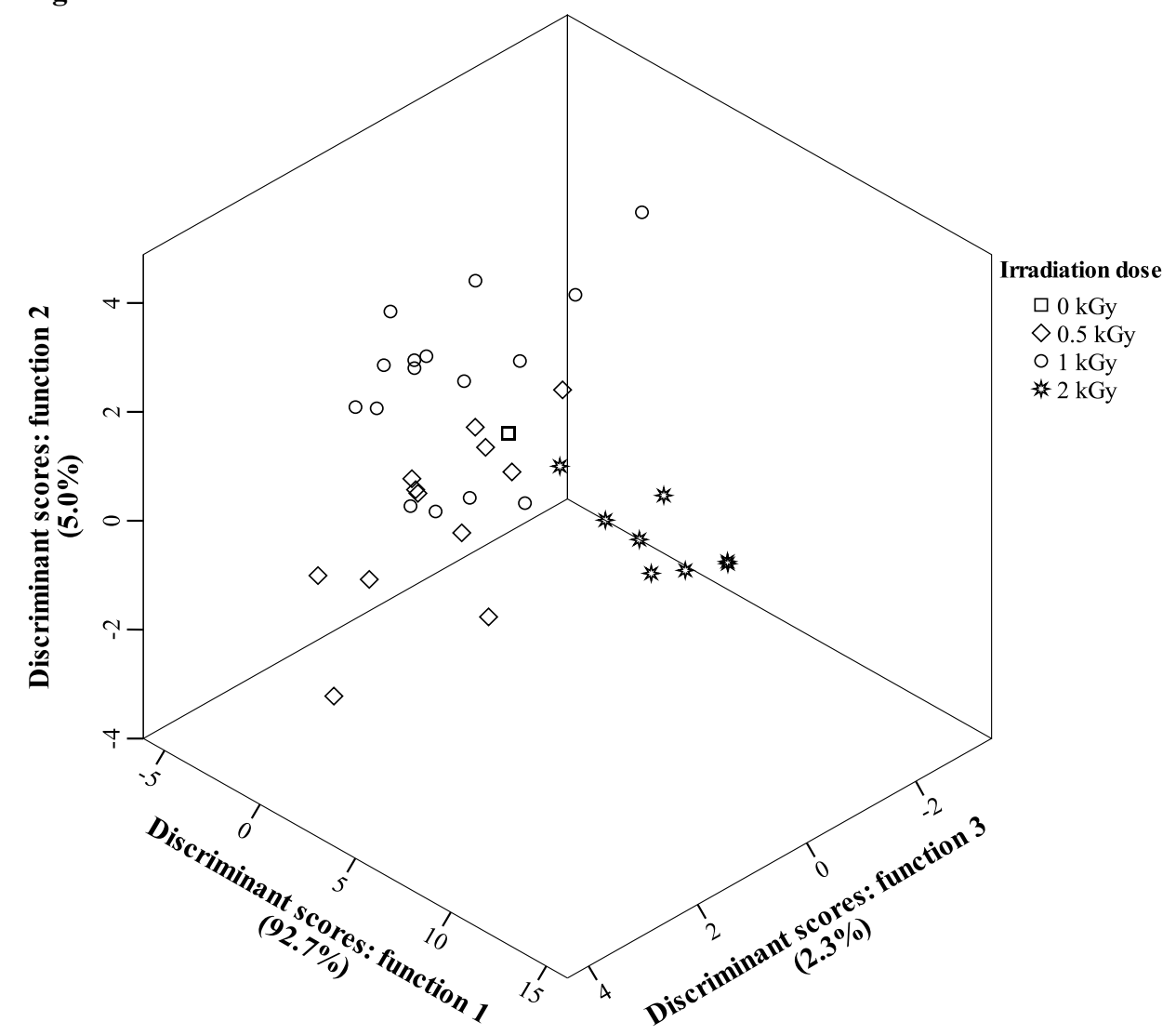

(a)

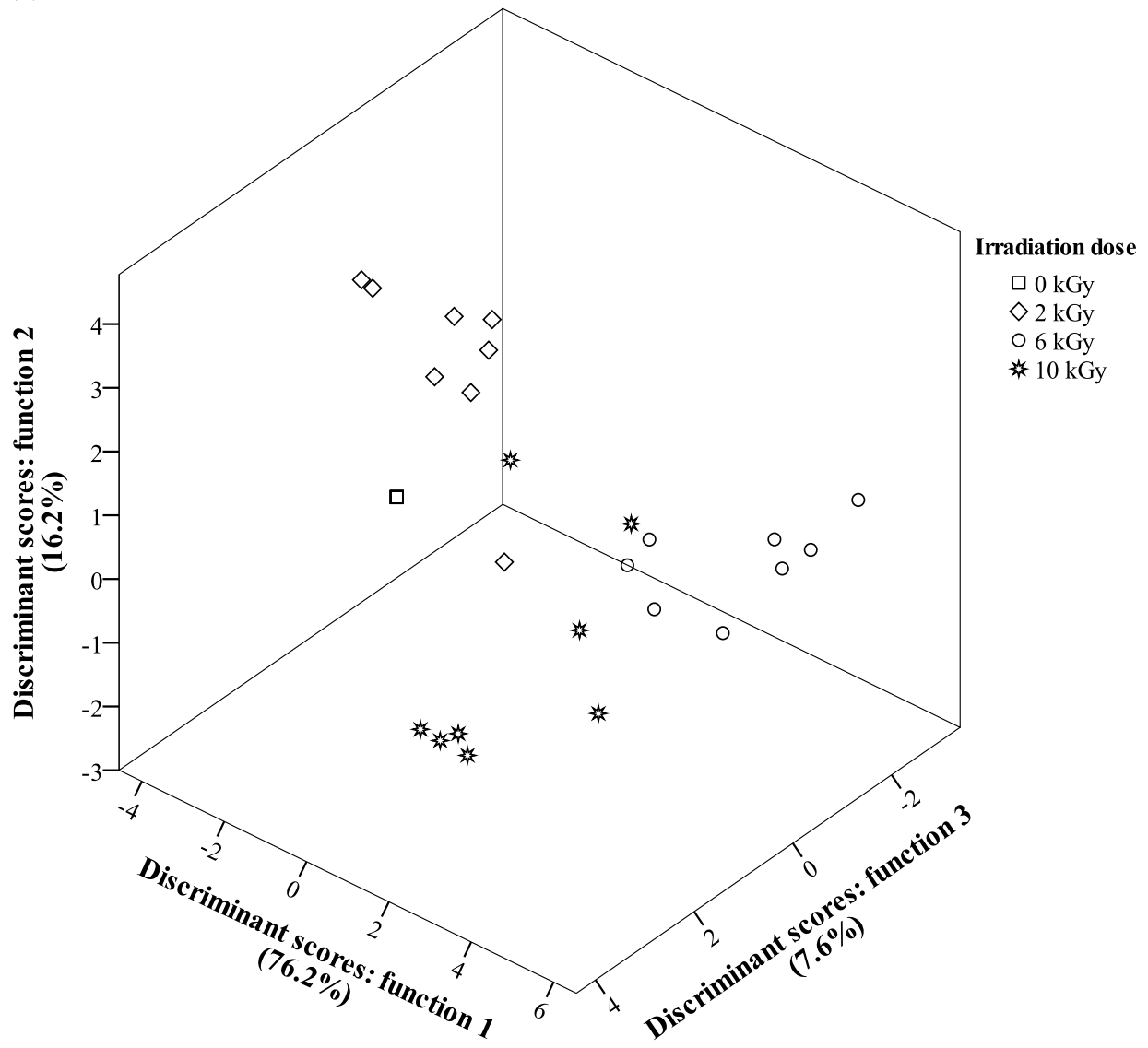

(b) 